Royal Signals. It is hoped that Dr. C. D. Stewart of Singapore, Dr. Jeffreys from Hong-Kong and one or two others stationed in the Far East may get short leave and join this party.

The programme includes spectrophotometry of the chromosphere by means of a series of short exposures on a moving plate held fixed for each exposure, a study of the extreme ultra-violet spectrum of the chromosphere and corona with a quartz spectrograph fed by aluminised mirrors in place of mirrors of speculum metal, a study of high-dispersion spectrograms of the limb near totality and of the chromosphere for accurate wavelengths, an examination with Nicol prisms and Savart prisms of the polarisation of the corona and of the surrounding regions of the sky, a study of the Fraunhofer lines in the spectrum of the outer corona and direct photography of the corona in the ultra-violet, photographic and infra-red regions.

If, as was not definitely known at the time of writing, Dr. Johnson of the California Institute of Technology comes to Japan, he will continue the investigations on the polarisation of the corona, which he carried out at the last eclipse.

Finally, we come to the list of Japanese expeditions, and here tribute must be paid to the Eclipse Committee of the Japanese National Research Council for the many steps taken to help the visiting observers. From the Tokyo Astronomical Observatory and the National Science Laboratory at Shanghai a party will proceed to Manchukuo to observe the eclipse from a station near the frontier. Director Sotome and other members of the staff of the Tokyo Astronomical Observatory will form three parties observing at Nakatonbetu, Abashiri and Monbetu : they will take photographs of the eclipse star field for the Einstein effect, and also take direct photographs of the corona. Prof. T. Tanaka, of the Physics Department of the Tokyo Imperial University, will examine the spectrum of the corona from the Mitsui Agricultural Farm near Syari; Director Okada and Dr. Sekiguti, of the Central Meteorological Observatory, will arrange observations of the eclipse from aeroplanes at Nemanbetu; Prof. Ono, of the Tokyo Bunrika University, will take observations of terrestrial magnetism, while Prof. S. Nakamura, of the Tôhoku Imperial University, will study earth currents and other geophysical phenomena at Kosimizu ; Prof. Matukuma, of the same university, will carry out further astronomical investigations, as also will Prof. Ueda and Prof. I. Yamamoto, of the Kyoto Imperial University.

No wide region of the eclipse track will be without its party of observers, and by general agreement, for the most part reached at the Paris meeting of the International Astronomical Union last year, the most important observations, where duplicated, are being made at well-separated stations. A reasonable amount of luck should secure from the successful parties a well-balanced body of fresh knowledge as to the upper layers of the solar atmosphere.

\title{
Late Cenozoic History in India
}

\section{By Dr. Hellmut de Terra, Research Associate in Geology, Carnegie Institution of Washington and Yale University}

$\mathrm{T}$ HE progress recently made in the prehistory and geology of man in China, Java and Africa called for an organised study of the late Cenozoic history in India, the importance of which as a promising research field had been previously recognised by men of science such as Pilgrim, Merriam and Hrdlička. The approach to this complex task was determined by geological considerations, inasmuch as the stratigraphy of the Pliocene-Pleistocene sequence had to take account of the young Himalayan mountain uplifts and related phenomena. Two previous expeditions of mine had given me an intimate knowledge of the geology in north-west India, and therefore I chose for my studies a stretch of country extending from the Kashmir valley across the Pir Panjal range and Poonch to the Salt Range between the
Rivers Indus and Jhelum. This sector comprises the slope of the main Himalaya and the adjoining plains in the Punjab with their more recently uplifted ridges.

The field work was carried out last year in association with Dr. Teilhard de Chardin who joined the expedition for the last three months, and with T. T. Paterson of the University of Cambridge. N. K. N. Aiyengar, of the Geological Survey of India, was in charge of the collecting of fossils, and D. Sen of the University of Calcutta acted as field assistant. Temporary associates of my party were H. J. H. Drummond and P. Krishnaswami.

The Pliocene formations, to which we also refer the Chinji-beds with Hipparion fauna, offered, as on my previous expedition in 1932, an opportunity 
of gathering additional fossil material, particularly of the higher primate group, of which some new genera had recently been described. Last year, twenty-five primate remains were collected, consisting of two jaws, a few maxilla and mandible fragments and isolated teeth. These fossils will be worked out by Prof. W. K. Gregory, who believes that their study will add substantially to our still meagre knowledge on the evolutionary trends among the man-like apes of late Tertiary time. glaciation, which Dainelli once referred to the Mindel advance in the Alps.

An important observation of ours was the merging of the 'Boulder Conglomerate' fans into ground moraines derived from the second ice advance. At Campbellpore, near the Indus, the Boulder Conglomerate carries erratic blocks and it overlies unconformably tilted fossiliferous early Pleistocene beds. In Kashmir also the older Pleistocene lake beds are folded and in Jammu

Table showtng the tate Cenozoio sequenoe in North-west India

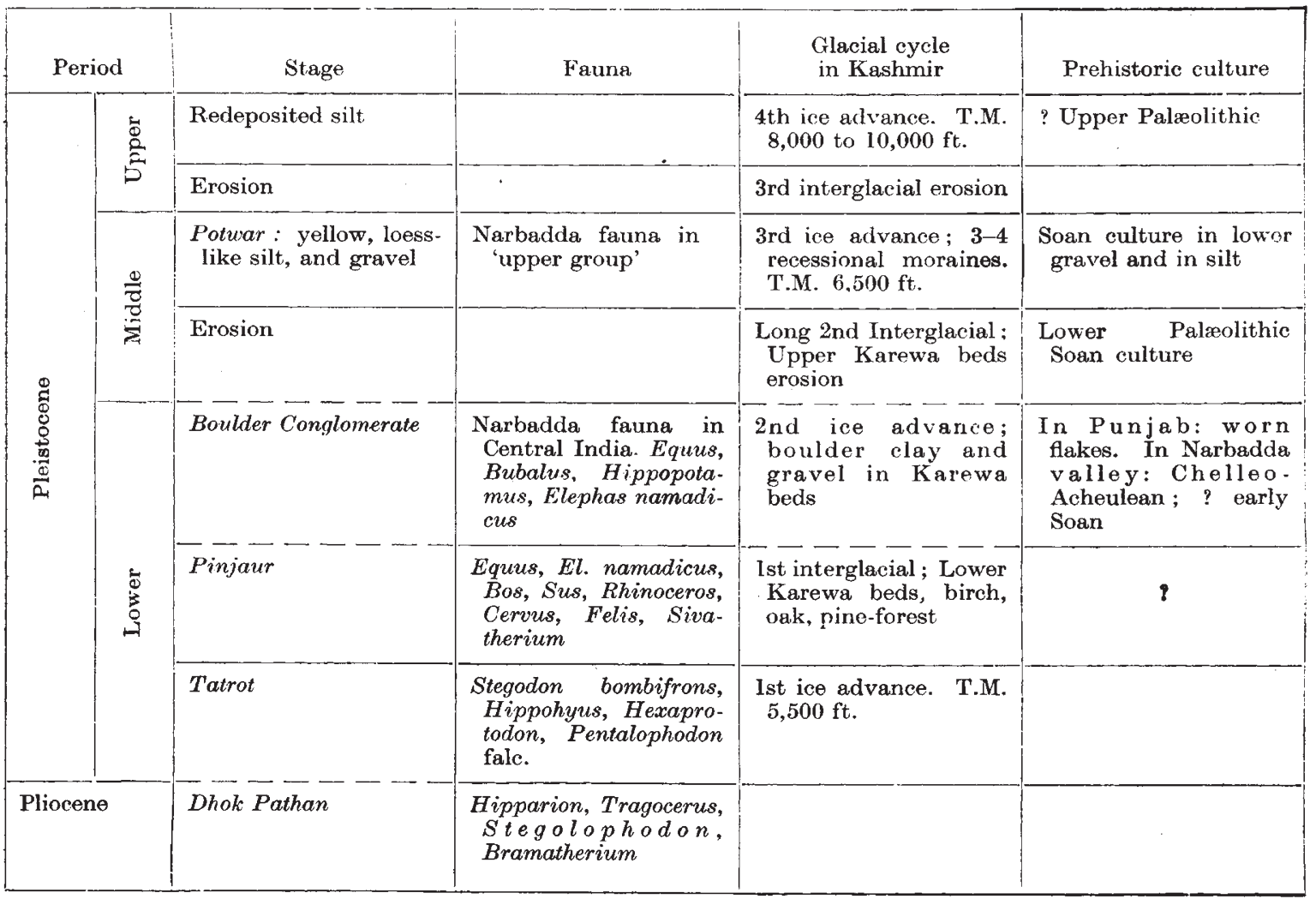

(T.M.- -levation of terminal moraine walls above sea-level. Broken lines-main unconformities.)

So far as our results on the Pleistocene succession in north-west India are concerned, they are briefly summarised in the accompanying table. This tabulated statement, however, should not be regarded as the ultimate résumé of my views, gained through field studies and clarified through repeated discussions with Dr. Teilhard and with Mr. Paterson. It may be seen that the Upper Siwalik stages, such as Tatrot, Pinjaur and Boulder Conglomerate (terms by Dr. Pilgrim) could be linked with the glacial cycle in Kashmir. Paterson and I surveyed and partly mapped the Pleistocene in Kashmir, and our views principally uphold Dainelli's theory of a fourfold Himalayan glaciation. However, we seem to differ from his views as regards the relative age of the first overthrust movements are clearly recorded from this period. A second major phase of diastrophism occurred during the second interglacial, and a third, but lesser one, after the third ice advance. We noticed a regional presence of five terraces in the valleys of Kashmir and of the plains which are clearly linked with the last two major glaciations and interglacial periods, and a minor late-glacial ice-advance.

The prehistoric cultures found in this area range from Early Palæolithic to Late Middle Palæolithic and Neolithic. The oldest is represented by worn flakes in the Boulder Conglomerate and by. bi-faces, cleavers and hand-axes associated with gravels of perhaps similar age. The Soan culture, named after the Soan River near Rawalpindi, is 
mainly a flake culture of distinct facies which may range from the Early to late Middle or even Upper Palæolithic. Workshops belonging to this Soan industry are numerous below the Potwar loess-like silt.

During the last two months, various excursions were made to Upper Sind, Central and Southern India. Along the Narbadda River, Dr. Teilhard and I collected Chellean and Acheulean tools from beds containing the Narbadda fauna of Middle Pleistocene age. Here also were found artefacts belonging to the Soan culture.

Paterson, Drummond and Krishnaswami studied the prehistoric collections in the museums at Lahore, Benares, Calcutta, Madras, Trivandrum, Colombo and Bombay, and field work was carried out by them in Madras and Bombay presidencies.
They reported a widespread occurrence of the Soan culture, of a microlithic industry, and of a proto-Neolithic culture. The early Neolithie in these collections appeared to be akin to that of northern Europe, though there occur types similar to the latest Upper Palæolithic of North Africa.

The artefact collection, numbering more than four thousand specimens, will be worked out by Paterson and Drummond at the Arehæological Museum of the University of Cambridge.

The researches were made possible through the support of the Carnegie Institution of Washington, the American Philosophical Society, the Royal Society of London and the University of Cambridge. The co-operative policy of the Government of India and of the Geological and Archæological Surveys of India is gratefully acknowledged.

\section{Food from Wood}

$\mathrm{T}$ HE suggestion has recently been made that as much food might be obtained per acre of woodland as per acre of arable land, if the wood be so treated as to yield sugar. The production of sugar from wood has been a subject of much research, especially in Germany and the United States. There is no doubt that it can be achieved, not only on a small laboratory scale but also in commercial plant operation; the difficulties that have had to be overcome have been those of chemical engineering rather than of chemical reactions. There is, however, a very real doubt whether such a process is justifiable, save perhaps in time of national emergency (for which purpose it was developed in Germany during the Great War), or whether it can ever be economically a sound proposition.

From a material point of view, timber is grown for two main purposes-either for use as a structural material or for its cellulose content. There are perhaps few structural uses of timber that could not be satisfied by other materials. Cellulose, however, is as yet quite indispensable, not merely as pulp and paper, but also in its myriad new uses for textiles or rayon, lacquers, cellophane, etc. To split up such a valuable raw material to sugar is certainly unsound from the point of view of the proper utilisation of natural resources, and only justifiable if-the products cannot be obtained from any other source. The agriculturist will answer that sugar of a purer and more usable type may be obtained directly from sugar beet, or from cane, or can be obtained far more simply from starchy crops such as potatoes or maize. Sugar beet is capable of yielding 2-3 tons of sugar per acre, and sugar cane $4-5 \frac{1}{2}$ tons per acre. The starch in potatoes amounts to $1 \frac{1}{2}-2$ tons per acre, or in maize, 1 ton per acre, equivalent to an almost equal weight of sugar.

To make a comparison of these yields with those possible from woodland is difficult, inasmuch as the latter is obviously not an annual crop. The faster growing soft woods (conifers) may be said to give more than 300 tons of timber per acre per 100 years, or 3 tons per acre per year. The maximum yield of wood sugar so far claimed is two thirds of the weight of the wood, or 2 tons per acre on an annual basis. This calculation is rather questionable because the annual rate of increase of saplings is much greater for the first ten to twenty years than at maturity, and the yield of wood sugar per acre obtainable from young growth might be at a higher level. Against this must be set the fact that the rate of growth of most woods is considerably below that of the very vigorous soft woods such as silver fir.

The most serious objection that can be raised to the process, however, is the nature of the sugar produced. Whereas cane and beet give almost exclusively sucrose, that from wood is a mixture of several sugars, not all of them of equal value as food to man or animals, or even of equal availability for biological fermentations. The chief constituents of woods are cellulose, hemicelluloses and lignin. The proportions found usually lie within the following | orcentage limits-cellulose, 50-60, hemicelluloses, 10-15, lignin, 20-30. The cellulose of woods is not identical with the standard cellulose of cotton, but contains considerable amounts of the pentosan-xylan-particularly in the case of 